\title{
Resident Duty Hours and the Delicate Balance Between Education and Patient Care
}

\author{
Diane B. Wayne, $M D^{7}$ and Vineet Arora, MD, MAPP ${ }^{2}$ \\ 'Department of Medicine, Northwestern University Feinberg School of Medicine, Chicago, IL, USA; ${ }^{2}$ Department of Medicine, University of \\ Chicago Pritzker School of Medicine, Chicago, IL, USA.
}

J Gen Intern Med 23(7):1120-1

DOI: $10.1007 / \mathrm{s} 11606-008-0671-4$

(c) Society of General Internal Medicine 2008

$\mathrm{S}$ ince the implementation of resident duty hour reform by the Accreditation Council for Graduate Medical Education (ACGME) in 2003, numerous studies have focused on the effects of duty hour reform on resident well-being and patient outcomes. Recent publications highlight the benefit of improved resident health, including reduced stress and burnout. ${ }^{1}$ Despite concerns regarding discontinuity of care, large national studies show that patient outcomes did not worsen, and may have even improved post duty-hour reform. ${ }^{2,3}$ While the Institute of Medicine ${ }^{4}$ and others consider the future of resident duty hours, it is equally important to examine possible spillover effects on other stakeholders in the teaching hospital hierarchy, namely faculty and medical students. There is increasing evidence that the loss of resident time has translated into increased faculty involvement in direct patient care. ${ }^{5}$ Medical educators also express concern regarding the impact of duty hours on medical student education. ${ }^{6}$ Two articles in the 2008 JGIM special issue on medical education specifically explore the effects of duty hour reform on academic faculty and medical students, and open the door for further investigation and analysis.

Goitein and colleagues ${ }^{7}$ surveyed faculty physicians at three hospitals affiliated with the University of Washington to assess the impact of resident work hour limitations on their professional lives. The majority of respondents reported an increase in clinical workload after 2003, with a median increase of 58 hours/week. Not surprisingly, faculty members also reported decreased academic and research time. It is particularly disturbing that $72 \%$ reported spending less time teaching residents and that $20 \%$ were more likely to leave academic medicine as a direct result of duty hour reform. Although this is a single-institution survey, respondents represent three hospital affiliates, are from more than one specialty, and confirm similar findings from a nationally representative sample of internal medicine faculty. ${ }^{8}$

In a second article in this issue, Reed and colleagues analyze data obtained from a survey of key clinical faculty $(\mathrm{KCF})$ at 40 internal medicine residency programs and report the perceptions of $\mathrm{KCF}$ on the impact of duty hour regulations on medical student education. ${ }^{9} \mathrm{KCF}$ spend 15 hours or more each week actively involved in residency education, and the majority (52\%) felt the overall quality of medical student education on inpatient medicine rotations worsened after 2003. Faculty most engaged in teaching were also the most likely to report a decrease in the quality of education. Limitations of this study include that students themselves were not surveyed and the respondents are $\mathrm{KCF}$ in residency programs and their role in medical student education is unclear.

Together, these studies illustrate the difficulty in ensuring the fine balance between education and direct patient care in teaching hospitals after the implementation of duty hour reform. Faculty members, who are participating in more direct patient care due to the absence of residents, have less time to teach. Although residents are working fewer hours, without a corresponding reduction in workload, they may be performing the same amount of work in less time. With increasing resident work compression, activities of patient care likely take precedence over teaching and education. Thus, resident and attending teaching activities (formal feedback on presentations and notes, literature review, order writing and test interpretation) may be reduced or eliminated. Increased work compression also places residents at risk of burnout. Legassie and colleagues, in a third article from this issue, demonstrate that burnout is still present in a substantial percentage of residents. ${ }^{10}$ This highlights that restricting duty hours alone is not enough to optimize the well-being and mental health of physicians-in-training.

What can be done to restore the educational mission in the setting of duty hour reform? The Association of Program Directors of Internal Medicine Task Force on the Learning Environment has issued a series of recommendations that address this issue. ${ }^{11}$ Reducing the clinical load of teaching services to preserve time for education and research is one possible solution. Shifting activities that are common but have low educational benefit (scheduling follow-up tests and appointments, blood draws) to non-physician staff may result in more time for education. The increased use of electronic medical records can also improve efficiency in clinical care, hopefully resulting in more time for teaching. However, the prohibitive costs of these solutions suggest the need for continued innovation to preserve educational time for faculty, residents, and students.

Curricula that are student-driven and less faculty intensive (computer tutorials and self-study modules) can be used to replace lectures and maximize bedside and small-group teaching. In addition, medical simulation should be used to 
preserve and even improve the preparation of resident and students in performing procedures and providing emergency care. Remunerating faculty for teaching has already been shown at one institution to improve quality ${ }^{12}$ and could also be used to improve efficiency by consolidating teaching efforts within a smaller group of talented educators. Residents should also receive formal instruction in their role as educators. For this to be effective, any "teaching to teach" curriculum must be integrated into residency training with the same priority as clinical topics.

On this 5-year anniversary of duty hour restrictions, we must continue to prioritize the quality of life and well being of our residents, and the delivery of high quality healthcare to our patients. However, as we reflect on the benefits to residents and patients, several reports from this issue build on prior work and suggest that duty hour limitations have had unintended consequences on education and faculty satisfaction. The financial cost to protect time for non-clinical activities is high, and it is unlikely that new funding sources for widespread support of teaching and research will be easily identified. Despite these obstacles, the time is now for teaching hospitals and medical schools to work together to design and test innovative mechanisms to restore the delicate balance between education and patient care.

Acknowledgement: Funding source: None

Conflicts of interest statement: None disclosed.

Corresponding Author: Diane B. Wayne, MD; Department of Medicine, 251 E Auron St, Galter 3-150, Chicago, IL 60611, USA (e-mail: dwayne@northwestern.edu).

\section{REFERENCES}

1. Myers JS, Bellini LM, Morris JB, et al. Internal medicine and general surgery residents' attitudes about the ACGME duty hours regulations: a multicenter study. Acad Med. 2006;81:1052-8.

2. Volpp KG, Rosen AK, Rosenbaum PR, et al. Mortality among hospitalized Medicare beneficiaries in the first 2 years following ACGME resident duty hour reform. JAMA. 2007;298:975-83.

3. Shetty KD, Bhattacharya J. Changes in hospital mortality associated with residency work-hour regulations. Ann Intern Med. 2007; 147:73-80.

4. Optimizing graduate medical trainee (Resident) hours and work schedules to improve patient safety. Institute of Medicine. Available at: http://www.iom.edu/CMS/3809/48553.aspx. Accessed May 3, 2008.

5. Schuster B. Tough times for teaching faculty. Arch Intern Med. 2007; 167:1453-5.

6. Kogan JR, Pinto-Powell R, Brown LA, et al. The impact of resident duty hours reform on the internal medicine core clerkship: results from the clerkship directors in internal medicine survey. Acad Med. 2006;81:1038-44.

7. Goitein L, Shanafelt TD, Nathens AB, Curtis JR. Effects of resident work hour limitations on faculty professional lives. J Gen Intern Med. 2008;23:Xxx-ss.

8. Reed DA, Levine RB, Miller RG, et al. Effect of residency duty-hour limits: views of key clinical faculty. Arch Intern Med. 2007;167(14):148792.

9. Reed DA, Levine RB, Miller RG. Impact of duty hour regulations on medical students' education: views of key clinical faculty. J Gen Intern Med. 2008;23:xxx-xx.

10. Legassie J, Zibrowski EM, Goldszmidt MA. Measuring resident wellbeing: imposturism and burnout syndrome in residency. J Gen Intern Med. 2008;23:xxx-xx.

11. Bellini L. Learning environment task force. Duty hours and beyond: work intensity and the learning environment. Association of program directors of internal medicine spring meeting. New Orleans, LA, April, 2008. Available at: http://www.im.org/AAIM/Meetings/PastMeetings/ 2008/APDIM/plenaryv,bellini.pdf. Accessed May 3, 2008.

12. Ashar B, Levine R, Magaziner J, Shochet R, Wright S. An association between paying physician-teachers for their teaching efforts and an improved educational experience for learners. J Gen Intern Med. 2007:22:1393-7. 